\title{
Research Square \\ Evaluation of job security among operating room nurses of teaching hospitals, Kermanshah University of Medical Sciences
}

\section{Yahya Safari}

Kermanshah University of Medical Sciences

Fatemeh Foroutanfar ( $\nabla$ f.foroutanfar75@gmail.com )

Kermanshah University of Medical Sciences

\section{Research article}

Keywords: Job security, job satisfaction, organizational commitment, nurses

Posted Date: February 26th, 2020

DOI: https://doi.org/10.21203/rs.2.24584/v1

License: (c) (i) This work is licensed under a Creative Commons Attribution 4.0 International License.

Read Full License 


\section{Abstract}

Background: This study assessed job security among operating room nurses of teaching hospitals, Kermanshah University of Medical Sciences in Kermanshah, Iran.

Methods: The population of this descriptive-analytical study included all operating room nurses $(n=217)$ of teaching hospitals affiliated to Kermanshah University of Medical Sciences in 2017, from whom 136 were chosen as study sample by simple random sampling and Kerjesi-Morgan table. Data were collected by Nissi's job security questionnaire. The obtained data were analyzed by Pearson'schi-square and oneway ANOVA tests.

Results: The findings showed the job security of the majority of nursing staff was average in low job displacement (66.9\%), job satisfaction (68.5\%), emotional work environment $(65.5 \%)$, sense of peace (71\%), organizational commitment (44.4\%) and organizational defense (55.6\%) domains. However, their job security was high in concentration on job (89.5\%) and choosing an appropriate job (90.3\%) dimensions and poor in financial satisfaction (71.8\%) domain. In general, $89.5 \%$ of nurses had a high job security. The results of Pearson's chi-square test showed a significant association between job security and gender, age, education and income variables. However, the findings of one-way ANOVA indicated no significant difference among different hospitals regarding the mean job security.

Conclusion: The findings of this study demonstrated $89.5 \%$ of the studied participants were reported to have job security. Also, among the studied hospitals, Mohammad Kermanshahi hospital was found to have the highest job security.

\section{Background}

Job security is a mental state of every career that indicates job stability rate in the future. Accordingly, job security is having the right to continue the job, which is usually continued until retirement to the extent that the staff feel secure they will not lose their job. On the other hand, job security is defined as having an appropriate job and confidence in its continuity in the futureas well as lack of factors threatening the proper working conditions of the given job.

Subjects like job changes, job loss and unavailability of a proper job have been included in job security, making the people uncertain about their job stability and expecting authorities to lay them off any moment because of unjustifiable reasons. On the other hand, job security is conceived of conditions in which an individual is not at the risk of losing or changing the job. Job security is achieved by ensured continuity of relationship between employment and organization. When taking about job security, the issue of official job and guaranteed salary and benefits are evoked in the mind. However, in the current world job security is not dependent upon official job and lifelong employment, while staff empowerment is the basis of job security. 
In the new concept of job security, organizations have to depend on the personnel so that they can meet the professional and social expectations of organization and enjoy job stability consequently. From the perspective of managers, job security is considered one of the main incentives of any person who wants to have a job. Job security to develop human resource in every organization is necessary for achieving the organizational objectives. The job security of the staff ensured by the senior manager of organization can lead to development of confidence in organization and consequently reduced intension to quit the job because job security is anessential criterionfor the staff to remain committed and continue their job in organization. Therefore, providing job security is beneficial for both the staff and organization. The tension caused by lack of job security is a factor affecting the tendency of staff to quit their job. Lack of job security include instances like uncertainty about continuity of the job, lack of confidence in provision of retirement, insecurity about temporary employment and failure to feel secure due to plotting against an employed or a dismissed person.

Lack of job security is an internal organizational factor that leads to job burnout and is followed by reduced efficiency of manpower. Operating room nursing has been one of the key jobs in healthcare environments, providing the patients with quality services. The operating room staff, unlike other nursing staff, are exposed to many problems and risks in their career. In the past years of the trade union demands, no special attention has been given to this walk of life, or they may have been forgotten.

The results of a theoretical research by Nazari et al. showed a significant relationship between job security and organizational commitment of physical education teachers. There was also a significant association between organizational commitment and job security components (concentration on job, job satisfaction, financial satisfaction, organizational reliance and organizational defense), but no significant relationship was observed among job displacement, choosing an appropriate job, emotional work environment and sense of peace. Moreover, there was a positive correlation between job satisfaction and organizational commitment. Furthermore, the results of regression analysis indicated satisfaction with salary and colleagues had a higher effect on organizational commitment; organizational commitment being a factor that reduces organizational negligence by itself.

In a study, Baferani reported a positively significant correlation between organizational commitment and job security components. No significant difference, however, was found between job security and organizational commitment and personnel's marital status and gender. On the other hand, there was a significant difference between job security and organizational commitment and staff's age, education and employment status .

Further, Alavi et al. found a significant association between job security and staff's gender, job experience and employment. But Taghizadeh et al. showed no significant difference between job security and organizational commitment and demographic characteristics, including age, education, job experience and gender.

Income is an important component of job security. Nikoukar et al. reported a significant relationship between satisfaction with income and job security. Also, Jandaghi\& Bahrami showed a significant 
difference between official and contractual staff regarding organizational commitment and job satisfaction. The findings of Mortazavi indicated a strong associationamong organizational commitment, job satisfaction and job security. Judge reported that job satisfaction caused an improvement in the quality of performance, a reduction in absence, delay and job burnout, an improvement in physical and psychological health and satisfaction with life. The results of the study by Faramarzi showed that job security enhanced efficiency and organizational commitment.

Because of job security, the staff's spirit is promoted in organization,and they learn the new job skills quickly. Sajadi et al. concluded that increasing the job security of personnel can increase their organizational commitment and reduce their tendency to quit their job. In their study, Verdipoor et al. concluded that higher job security was significantly correlated with job satisfaction among the staff. Based on the above-mentioned discussion and scarcity of studies on job security among operating room nurses, this study was conducted to assess job security among the operating room nurses of teaching hospitals of Kermanshah University of Medical Sciences in 2017.

\section{Methods}

The population of this descriptive-analytical study comprised of all operating room nurses $(n=217)$ of the teaching hospitals in Kermanshah, Iran. The study sample was calculated to be 136 nurses using Kerjesi-Morgan table, who were selected through cluster random sampling. It should be noted that data were gathered from $95.5 \%$ of the samples.

Since this study was designed based on a quantitative paradigm, a questionnaire was used for data collection. The first section of the questionnaire included 6 items which analyzed demographic characteristics, including age, gender, job experience (in years), education, employment, income and workplace. The second section of the questionnaire consisted of 9 job security components, including concentration on job, low job displacement, choosing an appropriate job, job satisfaction, financial satisfaction, emotional work environment, sense of peace, organizational commitment and organizational defense, which were included in 30 articles expressing the views of experts about issues related to job security in organization.

The maximum score for having job security in this scale was 120 and minimum score was 73 . The job security dimensions were classified in three categories, including low (0-33.33\%), average (33.34$66.67 \%)$ and high (66.68-100\%). Scoring the job security scale was done based on 5-point Likert scale; 1 = completely agree, 2 = disagree, $3=$ neutral, $4=$ agree and $5=$ completely agree. This scale was first used byKamali (2000) with acceptable reliability measuredby Cronbach's alpha. It was also used by Nissi \& Seyed Mahmoudian (2002). The validity of this scale was obtained to be 0.33 by correlating the total test score with the general question, and its reliability was found to be 0.90 by Cronbach's alpha. Further, Saghaeian (2012) used this questionnaire and reported the validity and reliability indices of 0.51 and 0.87 , respectively. Data analysis was performed by SPSS software using Pearson's chi-square and oneway ANOVA tests. 


\section{Results}

From 124 participants of this study, 88 were female. The results indicated the age range of 20-50 years for the study participants. As for education, 21 of them had associate degree, 98 had bachelor degree and 5 had master degree. With regard to job experience, the minimum work experience was 1 year and maximum work experience was 29 years. The majority of the staff were doing their post-graduation service, while a small number were officially employed.

Table 1. Mean and standard deviation of job security among operating room nurses in different hospitals

\begin{tabular}{|c|c|c|}
\hline Hospitals & Mean & Standard deviation \\
\hline Imam Reza & $88 / 2$ & $3764 / 0$ \\
\hline Taleghani & $02 / 3$ & $4404 / 0$ \\
\hline Imam Khomeini & $78 / 2$ & $5667 / 0$ \\
\hline Imam Ali & $95 / 2$ & $3587 / 0$ \\
\hline Mohammad Kermanshahi & $10 / 3$ & $1833 / 0$ \\
\hline Motazedi & $86 / 2$ & $2390 / 0$ \\
\hline Total & $92 / 2$ & $4178 / 0$ \\
\hline
\end{tabular}

As shown in Table 1, Mohammad Kermanshahi hospital had the highest mean job security (3.10) and Imam Khomeini hospital had the lowest mean job security (2.78) from among the studied hospitals.

Table 2. Frequency distribution of job security dimensions of operating room nurses in the teaching hospitals of Kermanshah University of Medical Sciences

\begin{tabular}{|c|c|c|c|}
\hline \multirow{2}{*}{$\begin{array}{c}\text { Frequency } \\
\text { Job security } \\
\text { Dimensions }\end{array}$} & $\begin{array}{c}\text { Low } \\
(0-33.33 \%)\end{array}$ & $\begin{array}{c}\text { Average } \\
(33.34-66.67 \%)\end{array}$ & $\begin{array}{c}\text { High } \\
(66.68-100 \%)\end{array}$ \\
\cline { 2 - 4 } & Number (\%) & Number (\%) & Number (\%) \\
\hline Concentration on job & $(4) 5$ & $46(37 / 1)$ & $73(58 / 9)$ \\
\hline Lower job displacement & $28(22 / 6)$ & $83(66 / 9)$ & $13(10 / 5)$ \\
\hline Choosing a proper job & $(0) 0$ & $12(9 / 7)$ & $112(90 / 3)$ \\
\hline Job satisfaction & $11(8 / 9)$ & $85(68 / 5)$ & $28(22 / 6)$ \\
\hline Financial satisfaction & $89(71 / 8)$ & $30(24 / 2)$ & $5(4)$ \\
\hline Emotional work environment & $15(12 / 1)$ & $75(60 / 5)$ & $34(27 / 4)$ \\
\hline Sense of peace & $34(27 / 4)$ & $88(71)$ & $2(1 / 6)$ \\
\hline Organizational commitment & $55(44 / 4)$ & $55(44 / 4)$ & $14(1 / 3)$ \\
\hline Organizational defense & $50(40 / 3)$ & $69(55 / 6)$ & $5(4)$ \\
\hline
\end{tabular}

Table 3. Frequency distribution of job security dimensions of operating room nurses in the teaching hospitals of Kermanshah University of Medical Sciences in 2017 


\begin{tabular}{|c|c|c|}
\hline Job security & Number & Percentage \\
\hline Score less than 73 (lack of job security) & 13 & 5.10 \\
\hline Score more than 73 (with job security) & 111 & 5.89 \\
\hline Total & 124 & 100 \\
\hline
\end{tabular}

As shown in Tables 2 and 3, the results of job security questions are presented in nine dimensions. The job security of the majority of nursing staff was average in low job displacement (66.9\%), job satisfaction (68.5\%), emotional work environment (65.5\%), sense of peace (71\%), organizational commitment (44.4\%) and organizational defense (55.6\%) dimensions. The job security level was high in concentration on job (58.9\%) and choosing a proper job (90.3\%) dimensions and low in financial satisfaction $(71.8 \%)$ dimension. In general, $89.5 \%$ of nurses hada high job security.

Table 4. Results of Pearson's chi-square test for the association of demographic variables with job security of operating room nurses of teaching hospitals of Kermanshah University of Medical Sciences

\begin{tabular}{|c|c|c|}
\hline Variables & \multicolumn{2}{|c|}{ Chi-square results } \\
\hline Gender & $\mathrm{p}=0 / 022$ & ${ }_{\square} \square=822 / 49$ \\
\hline Age & $\mathrm{P}=009 / 0$ & ${ }_{\square}{ }_{\square}=722 / 84$ \\
\hline Education & $\mathrm{p}=0 / 017$ & ${ }_{\square}{ }_{\square}=488 / 97$ \\
\hline Job experience & $\mathrm{p}=442 / 0$ & ${ }_{\square}{ }=269 / 87$ \\
\hline Employment & $\mathrm{p}=53 / 0$ & ${ }{ }_{\square}=020 / 156$ \\
\hline Income & $\mathrm{p}=0 / 045$ & ${ } \square=955 / 107$ \\
\hline
\end{tabular}

According to Table 4, the results of Pearson's chi-square test showed a significant association between job security and age, gender, education and income at 0.5 error level.

Table 5. Results of one-way ANOVA for the mean difference of job security among the teaching hospitals of Kermanshah University of Medical Sciencesin 2017

\begin{tabular}{|c|c|c|c|c|}
\hline Sources of change & Sum of squares & Df & F & P-value \\
\hline Between groups & 162.1 & 5 & 1.351 & 248.0 \\
\cline { 1 - 3 } Within groups & 310.20 & 118 & & \\
\hline Total & 472.21 & 123 & & \\
\hline
\end{tabular}

As shown in Table 5, the $\mathrm{F}=1.351$ and $p$-value $>0.05$ are indicative of no significant relationship among various hospitals in terms of mean job security at 0.05 error level. 


\section{Discussion}

This study was aimed to evaluate job security among operating room nurses of teaching hospitals affiliated to Kermanshah University of Medical Sciences. The findings showed a significant association between job security and staff's age and education. Baferani also reported a significant difference between job security and variables such as age and education. This might be due to higher effect of age and education on the work experience of the personnel and consequently their job security. Accordingly, the results of Alavi et al. showed a significant difference between job security and gender among the staff, which might be because of higher vulnerability of the female than male personnel. On the other hand, women feel more limitations at workplace ${ }^{14,15}$.

Moreover, the results of this study were in line with those of Nazari et al., indicating a significant difference between the job security of women and men. In addition, the findings revealed no significant relationship between job security and work experience ${ }^{2}$. These findings were in agreement with those of Taghizadeh et al., probably due to the reduced motivation of the staff with more work experience gained over the years. On the other hand, the young personnel have more energy to provide services ${ }^{2,7}$.

Furthermore, the results indicated a significant association between income and job security, confirming the findings of Nikoukar et al. However,the findings showed no significant difference between job security and employment. This might be due to the fact that in the current world job security is not dependent on official and lifelong employment, while empowerment of the staff is the basis of job security. This result is in contrast with those of Alavi and Baferani showing the significant difference between job security and employment ${ }^{14,15,16}$.

\section{Conclusion}

The findings of this study showed most of the nurses had high job security. Identification of factors affecting the job security of personnel can help the managers of healthcare centers to train the motivated workforce by providingan appropriate work environment so that they make their greatest effort on patient care and achievement of organizational objectives. Another important findings was related to the job security of the studied hospitals, indicating that Mohammad Kermanshahi hospital had the highest level of job security. It is quite evident that rewards, equipment, relationship with colleagues, etc. can increase the job security.

\section{Declarations}

\section{Ethics declaration}

\section{Ethics approval and consent to participate}

In our country, these studies do not have ethical apologies, so there is no need for ethical approval and participant satisfaction. The authors collected data using informed consent from the research sample 
and voluntarily completed the questionnaires. . This study has no ethical problems.

\section{Consent for publication}

Not applicable

\section{Competing interests}

The authors declare that they have no competing interests.

\section{Funding}

The author (s) did not receive any financial support for the research, authoring or publication of this article.

\section{Acknowledgements}

The authors appreciate the cooperation of the operating room staff and nurses of the teaching hospitals of Kermanshah University of medical Sciences.

\section{Authors' Contribution}

All of the authors approved the content of the manuscript and contributed significantly to research involved the writing of the manuscript.

\section{Financial disclosure}

The authors declared that there is no conflict of interest.

\section{References}

1. Javedl. R., SiddiquiKh. A.Examining the Impact of Job Security,OrganizationalClimateand Engagement on Motivation Level of Employees at IMC PVT LTD.European Journal of Business and Management. 2012; 4(9):27_35.

2. Nazari F, Soori A, Eydi H.The prediction of organizational commitment of physical education teachers in Kermanshah province through job security and its components. Research on sports management and motor behavior.2015;11(21):175-184.

3. Aarabi S.M.Strategies, plans, and solutions for implementing appropriate job security in the administrative system. Management Studies Quarterly.2001;8(29,30):7-31.

4. Dabirinia J,Razavidinaee E, Afshan S.A. Investigating factors affecting the job security of journalists in Hormozgan province. Hormozgan Cultural Policy Paper.2016;6(11):68-85.

5. KHalaveh E, Mahdad A. Predict the perception of job security and organizational trust through moral leadership and adherence to psychological well-being. Journal of Ethics in Science and 
Technology.2015;10(4):37-44.

6. MehrabiJ,Golnari M. The Relationship between Job Security and Organizational Citizenship Behavior of Permanent and Temporary Employees in Qazvin University of Medical Sciences. Management Development and Development.2016; (21):49-60.

7. Taghizadeh J, Rasooli R, Bbaee SH.The Impact of Organizational Justice and Occupational Safety on Organizational Commitment through Trust to Managers. Human Resource Management Resume of Imam Hossein University. 2015;7(2):53-77.

8. RaeesiP,Mohebifar R. Job motivation from the perspective of staff and managers of educational hospitals of Qazvin University of Medical Sciences. Journal of Qazvin University of Medical Sciences.2006;10(1):101-108.

9. Fadaei, M, Barazandeh,S, Eshraghi, H(2015). INVESTIGATION OF THE EFFECT OF JOB SECURITY ON ORGANIZATIONAL COMMITMENT IN THE SOCIAL SECURITY ORGANIZATION (EAST TEHRAN GENERAL DEPARTMENT).Indian Journal of Fundamental and Applied Life ,Vol .5pp: 1130_1141.

10. Piryaei S, Arshadi N, The effect of job security and organizational justice on turnover intention: Mediating role of trust in tap management. Quarterly Journal of career \& organizational counseling.2012;4(11):78_94.

11. Ebrahiminezhad M, Ebrahiminezhad GH.R, Yarinaserieh M. Investigating the relationship between organizational stresses and employees' willingness to leave in government agencies.Daneshgar's Two-monthly Journal of Behavior, Management and Progress, University of Science and Technology 2009;16(38)35-43.

12. ZaminiS,Hoseininasab D, Zamini S, Zareie P. The Relationship between Organizational Culture and Job Satisfaction and Burnout among Tabriz University Staff.Health Quarterly of Iran. 2011;8(1)3040.

13. Asgari M, Rafat A, Rashedi V. Evaluation of job satisfaction of operating room technicians in Hamadan University of Medical Sciences Hospitals, 2011. Research Scientist 2012;11(1):37-40.

14. Baferani MJ. Investigating the Relationship between Job Security and Organization Commitment of PayameNoorastan University Staff in Hamadan, MSc, Isfahan University.2008.

15. Alavi SS, Alaghemandan H, Jannatifard F.(2013). Job security at isfahan university of medical sciences :implicatins on employees and types of contracts, Mater Sociomed.

Doi:10.5455/msm.2013.25.64.67.

16. Nikookar GH. H, GHorbanizadeh V.A, Eshaghi A. Examining some of the factors affecting middle managers' job security. Human Sciences Magazine 2007;16(70)58-78.

17. Jandaghi, Gh. Mokhles, A. Bahrami, H. The impact of job security on employees' commitment and job satisfaction in Qom municipalities. African Journal of Business Management. 2011;5 (1 6); 68536858.

18. Mortazavi.SH, Study of job satisfaction, organizational commitment and job security of employees in Government agencies.Management studies, labor productivity, Tehran, Beheshti University.1995. 
19. Judge. T.A, \&Wateanabe,s, Another look at the job satisfacation -life satisfacationrelationship, Journal of Applied Psychology.1993;87(6);936 -948.

20. Faramarzi M. Relationship of feeling of security and happiness with employees of Shiraz HempEnergy Co., Master's Thesis, Psychology, Industrial and Organizational Trend, Azad Islami University and Wardamdr. 2012.

21. Sajadi,H., Khamesi, M., Hasanzade, A., Vali, L. Organizational commitment and intention to leave the department supports the University staff. Iran Occupational Health Journal.2009; 6. (3):32-40.

22. Verdipoor H.A. Narimani M.R, Jahantab M, GHodoosinezhad J, Baghbanbaghestan E. Factors Affecting Job Satisfaction among Educational Hospitals of Urmia University of Medical Sciences Journal of Health Image.2013;4(4):31-37. 